\title{
The role of uterine artery embolization in management of abnormal uterine bleeding
}

\section{Ahmed M. Khalaf-Awad ${ }^{* a}$;Ahmed H.Abdellah ${ }^{\mathrm{b}}$; Ahmed Okasha Mohamed ${ }^{\mathrm{a}}$;Ghada M.Abdelrazek ${ }^{\mathrm{a}}$}

${ }^{a}$ Department of Diagnostic and Intervention Radiology, Faculty of Medicine, South Valley University, Qena 83523, Egypt.

${ }^{\mathrm{b}}$ Department of Obstetrics \& Gynecology, Faculty of Medicine, South Valley University, Qena 83523, Egypt

\section{Abstract}

Background:Abnormal uterine bleeding is a common presenting symptom in the family practice setting. The most common causes are uterine fibroids, dysfunctional uterine bleeding and adenomyosis. All conditions were accompanied by chronic blood loss disabling normal lifestyle with variable degrees of morbidity.

Objectives: This study is aiming to evaluate the safety, efficacy, and complications of uterine artery embolization(UAE) in the management of abnormal uterine bleeding (AUB)in different age groups.

Patients and Methods: This a prospective randomized clinical trial prospective study included 20 patients referred for UAE. Twelve patients had uterine fibroids, 4 patients had adenomyosis and other 4 patients were diagnosed as dysfunctional uterine bleeding. The embolizing materials were used including Polyvinyl alcohol, Tris- acryl gelatin microspheresand gelatin sponge. All patients had AUB.

Results: Most patients showed good therapeutic responses through the follow up period (6-12 months). Complete control of bleeding was achieved in $90 \%$ of patients and recurrence occurred only in $10 \%$. There was complete improvement of the pelvic pain and bulk related symptoms. Reduction of uterine and fibroid size occurred with average uterine and dominant fibroid volumes loss of $39 \%$, and $57 \%$ respectively. However, the reduction in the Junctional zone thickness was $5.6 \%$.

Conclusion: UAE is considered minimally invasive, safe, and effective method that plays an important role in treatment of variable types of AUB causes, aiming for uterine preservation and avoiding hysterectomy giving the chance for future fertility. It has high success rate with obvious low morbidity and mortality rates.

Key words: intervention, radiology, abnormal uterine bleeding, uterine artery embolization (UAE), embolization.

\section{Introduction:}

Abnormal uterine bleeding (AUB) is a common condition that increases healthcare costs and reduces quality of life (Marnach et al., 2019).

AUB can be defined as any variation from the ordinary menstrual cycle, which includes changes in regularity, frequency and length of menses or quantity of blood loss (Munro, 2016).

The International Federation of Gynecology and Obstetrics (FIGO) System 2 abbreviation PALMCOEIN (polyp[s], adenomyosis, leiomyoma, malignancy, coagulopathy, ovulatory dysfunction, endometrial disorders, iatrogenic, and not yet classified) systematically defines the most well- known reasons for abnormal uterine bleeding in a non-pregnant lady with structural (PALM) and nonstructural (COEIN) causes (Munro, 2017).

Uterine fibroids are the widely known pelvic tumors. Symptoms incorporate painful or heavy menses and mass-related symptoms, for example, pelvic pressure, urinary frequency, bowel symptoms, or reproductive dysfunction (Stewart, 2015).

Adenomyosis is asymptomatic in about $33 \%$ of cases, ladies may give heavy or irregular bleeding, dysmenorrhea, or dyspareunia (Benagiano et al., 2014). 
Transvaginal sonography (TVS) is relatively inexpensive, needs no anesthesia and being noninvasive, it can be the initial diagnostic step in the assessment of AUB. While MRI is an excellent preoperative imaging modality that helps identify and characterize uterine fibroids as well as exclude other relevant pathology such as adenomyosis and necrotic fibroids (Moss and Christie, 2016).

Uterine artery embolization (UAE) is accomplished for the treatment of an assortment of obstetric and gynecologic disorders, including uterine fibroids, adenomyosis, postpartum hemorrhage, and uterine arteriovenous malformations. It is considered an insignificantly invasive nonsurgical choice for treating uterine fibroid in poor surgical applicants and those who wish to avoid myomectomy or hysterectomy (Armstrong et al., 2019). This prospective study is aiming to assess and evaluate the safety, efficacy, and complications of uterine artery embolization in the management of abnormal uterine bleeding in different age groups.

\section{Patients and methods:}

This a prospective randomized clinical study was performed on twenty patients, with an age range from 21 to 55 years (mean age 38 years), referred from the Obstetrics and Gynecology departments as well as outpatient clinics. The study was done at the interventional radiology unit at Nasser Institute for research and treatment from June 2018 to June 2020.

All patients complained from abnormal uterine bleeding not responding to medical treatment. Twelve of them were complaining from symptomatic uterine fibroids, four patients had adenomyosis and other four patients were diagnosed as dysfunctional uterine bleeding. All were referred seeking for UAE as a minimally invasive procedure to control uterine bleeding and desiring uterine preservation.

Inclusion criteria: Includes patients with abnormal uterine bleeding not responding to medical treatment, these patients who were not fit for surgical interference, seeking for minimally invasive therapy, refusing hysterectomy for fertility preservation and patients with symptomatic uterine fibroids.

Exclusion criteria: Patients with a known history of contrast hypersensitivity, renal impairment, bleeding tendency, suspected pregnancy, pelvic inflammatory disease or other pelvic infection and endometritis, or uterine or cervical malignancy.

Pre-Procedure Evaluation: All patients were subjected to the following: Full detailed preprocedure history taking that included the menstrual history, type, duration and amount of bleeding, any medications, or chronic illness. Laboratory assessment including CBC, Hgb level, prothrombin time and concentration, INR, and kidney function. Pre-procedure transvaginal ultrasound examination and/ or pelvic MRI.

Procedure Evaluation: Transcatheter uterine artery embolization using PHILIPS ADVANCED ALLURA XPER FD20 X-RAY SYSTEM. The machine can perform serial radiography, digital subtraction, and road map images. Non-ionic contrast media (OMNIPAQUE 300 (Iohexol)) was used in all patients. Puncture Access needle, $6 \mathrm{Fr}$ vascular femoral sheath, 0.035 hydrophilic guidewire (Radiofocus Inc), 5 Fr Cobra catheter (Angiodynamic / Cordis Inc) and 2.4-3 Fr Renegade ${ }^{\circledR} \mathrm{Hi} \mathrm{Flo}^{\mathrm{TM}}$ Microcatheter (Boston Scientific, Natick, MA) were used. Different embolizing materials were used in our study including mainly permanent embolizing particles like PVA and TAGM (Embosphere) as well as temporary embolizing materials as gelatin sponge (Gel foam).

The endpoint of embolization depends on the uterine pathology to be treated; in uterine fibroid, embolization is continued until there is complete occlusion of the branch arteries penetrating the leiomyoma up to the distal main uterine artery. While in dysfunctional uterine bleeding and diffuse adenomyosis embolization was terminated once complete occlusion of the distal uterine artery spiral branches was achieved

Post-procedure follow-up: using transvaginal ultrasound - pelvic MRI examination - CBC - Clinical follow-up visits starting 3 months after the procedure and lasting up to 12 months.

\section{Statistical Analysis:}

-The collected data were coded, tabulated, and statistically analyzed using the SPSS program (Statistical Package for Social Sciences) software version 26.

-Descriptive statistics were done for parametric quantitative data by mean, standard deviation, and minimum\& maximum of the range, while they 
were done for categorical data by number and percentage.

-Analyses were done for parametric quantitative data using paired samples T-test.

-The level of significance was taken at (P-value < $0.05)$

\section{Results:}

The age of our study group twenty females ranged from 21- 55 years old with mean age of $38.90 \pm 7.026$ years. As regards the menstrual status, all patients were at the pre-menopausal period.

\section{Table (1)}

All patients had AUB with different etiologies, accompanying other symptoms where, sixteen patients $(80 \%$ of all patients) had anemia $(\mathrm{Hb}<12$ g/Dl.) because of blood loss, so three of them required blood transfusion (15\%). Urinary symptoms were the compliant of 12 patients (60\%). All patients complained of pelvic pain; 8 $(40 \%)$ of them had sciatica, and six $(30 \%)$ patients had bowel symptoms. Table (2)

According to the etiology of uterine bleeding, patients were divided into, dysfunctional uterine bleeding; including 4 patients (20\%), symptomatic uterine fibroids; including 12 patients $(60 \%)$, and Adenomyosis; Four patients (20\%). The types of uterine bleeding encountered among the patients was different regardless the etiology, where nine patients $(45 \%)$ had menometrorrhagia, nine patients $(45 \%)$ had menorrhagia, and two patients (10\%) had polymenorrhea.

In uterine fibroids group, 11 out of 12 patients $(91.7 \%)$ showed complete response with no bleeding post embolization. Only one patient showed recurrence of bleeding and underwent hysterectomy post embolization despite apparent technical success. Complete correction of anemia was obtained in all nine patients who had preembolization anemia in this group. Ten patients showed urinary symptoms in addition to uterine bleeding, all of them showed complete improvement of these symptoms.

In adenomyosis group, 3 out of 4 patients (75\%) had complete treatment response with no more bleeding after the procedure till the end of the follow up period. One patient (25\%) had recurrence of bleeding and underwent hysterectomy. Successful correction of pelvic pain, anemia and sciatica was obtained in all patients in this group.
In dysfunctional uterine bleeding (DUB) group, all patients had complete treatment response with no more bleeding till the end of the follow up period. Successful correction of pelvic pain and anemia was obtained in all patients.Figure (1)

The range of uterine volumes were $60-1134 \mathrm{cc}$ (mean $=332.52 \pm 258.50 \mathrm{cc}$ ) on pre-embolization US and MRI images compared to 54-630 $\mathrm{cc}$ (mean= $203.55 \pm 150.60 \mathrm{cc})$ on post-embolization images, which equals $39 \%$ reduction in size. The range of dominant fibroid volumes were 40-768 $\mathrm{cc}$ (mean $=$ $178.85 \pm 196.34 \mathrm{cc}$ ) on pre-embolization US and MRI images compared to 18-252 cc (mean $=75.71 \pm 64.85 \mathrm{cc}$ ) on post-embolization images, this equals $57 \%$ reduction in fibroid size. The range of Junctional zones thickness were 13-20 cc (mean = $14.875 \pm 3.42 \mathrm{cc}$ ) on pre-embolization US and MRI images compared to $12-18.5$ cc (mean $=14.00 \pm 3.028 \mathrm{cc}$ ) on post-embolization images, this equals $5.6 \%$ reduction in Junctional zone thickness.Table (3)

Arterial occlusion was done by polyvinyl alcohol (PVA) in 15 out of 20 patients (75\%), using different particle sizes 355-500 $\mu \mathrm{m}, 500-710 \mu \mathrm{m}$ and $700-900 \mu \mathrm{m}$. Tris-acryl gelatin microspheres (TAGM) (Embosphere 300-500 and 500-700 $\mu \mathrm{m}$ ) were used in seventeen patients. Gel foam particles was also used in two patients (10\%), in one of them it was used in combination with PVA, and in the other patient it was used in combination with PVA and TAGM. Table (4)

Minor complications were encountered in 5 patients; three patients had post-embolization syndrome in form of abdominal and pelvic pain, transient vomiting, and fever. one patient developed post procedure pelvic infection with infected vaginal discharge, and delayed return of menses (transient amenorrhea) in one case. No puncture site hematoma was encountered. Post procedure recurrence of bleeding occurred in two patients (10\%) after the procedure (within 6-12 months after embolization) and the two underwent hysterectomy. Table (5) 
Table (1): Demographic data of the patients:

\begin{tabular}{|c|c|c|}
\hline & \multicolumn{2}{|c|}{ Descriptive statistics (n=20) } \\
\hline & Frequency & Percent \\
\hline Age & \multicolumn{2}{|c|}{$(21-55)$} \\
\hline Range & \multicolumn{2}{|c|}{$38.90 \pm 7.026$} \\
\hline Mean \pm SD & & 100 \\
\hline Menstrual status & 20 & 0.0 \\
\hline Premenopausal & 0 & \\
\hline Postmenopausal & & \\
\hline
\end{tabular}

Table (2): pre-operative symptoms of the patients $(\mathrm{n}=20)$

\begin{tabular}{|c|c|c|}
\hline Symptom & Frequency & Percent \\
\hline Uterine Bleeding & 20 & $100 \%$ \\
\hline Anemia & 16 & $80.0 \%$ \\
\hline $\begin{array}{c}\text { Urinary } \\
\text { Symptoms }\end{array}$ & 12 & $60.0 \%$ \\
\hline Pelvic Pain & 20 & $100 \%$ \\
\hline Sciatica & 8 & $40.0 \%$ \\
\hline Bowel Symptoms & 6 & $30.0 \%$ \\
\hline Blood transfusion & 3 & $15.0 \%$ \\
\hline
\end{tabular}

Table (3): Radiological treatment response based on uterine, fibroid size, and Junctional zone thickness.

\begin{tabular}{|c|c|c|c|}
\hline & $\begin{array}{c}\text { Pre- } \\
\text { treatment }\end{array}$ & $\begin{array}{c}\text { Post- } \\
\text { treatment }\end{array}$ & $\begin{array}{c}\mathbf{P} \\
\text { value }\end{array}$ \\
\hline \multicolumn{4}{|l|}{$\begin{array}{l}\text { Uterine } \\
\text { volume }(n=20)\end{array}$} \\
\hline Range & $(60-1134)$ & $(54-630)$ & $\begin{array}{c}<0.001 \\
*\end{array}$ \\
\hline Mean \pm SD & $\begin{array}{c}332.52 \pm 258 \\
.50\end{array}$ & $\begin{array}{c}203.55 \pm 15 \\
0.60\end{array}$ & \\
\hline \multicolumn{4}{|l|}{$\begin{array}{l}\text { Dominant } \\
\text { Fibroid volume } \\
(n=12)\end{array}$} \\
\hline Range & $(40-768)$ & $(18-252)$ & $0.023^{*}$ \\
\hline Mean \pm SD & $\begin{array}{c}178.85 \pm 196 \\
.34\end{array}$ & $\begin{array}{c}75.71 \pm 64 \\
85\end{array}$ & \\
\hline \begin{tabular}{|l|} 
Junctional \\
zone
\end{tabular} & & & \\
\hline
\end{tabular}

\begin{tabular}{|l|c|c|c|}
\hline $\begin{array}{l}\text { (Adenomyosis) } \\
(\mathbf{n = 4})\end{array}$ & $(13-20)$ & $(12-18.5)$ & $0.003 *$ \\
\hline Range & $\begin{array}{c}14.875 \pm 3.4 \\
2\end{array}$ & $\begin{array}{c}14.00 \pm 3.0 \\
28\end{array}$ & \\
\hline Mean \pm SD & & & \\
\hline
\end{tabular}

Paired samples T test: for pairwise comparison of quantitative data within one group.

*: Significant difference at $\mathrm{P}$ value $<0.05$.

Table (4): Types of embolizing materials used in patients.

\begin{tabular}{|l|l|l|l|}
\hline \multicolumn{1}{|l|}{ Embolizing materials } & Frequency & Percent \\
\hline \multirow{2}{*}{ Permanent } & $\begin{array}{l}\text { Polyvinyl } \\
\text { alcohol (PVA) }\end{array}$ & 15 & $75 \%$ \\
\cline { 2 - 4 } & $\begin{array}{l}\text { Tris-acryl } \\
\text { Gelatin } \\
\text { microspheres }\end{array}$ & 17 & $85 \%$ \\
\hline Temporary & Gel foam & 2 & $10 \%$ \\
\hline
\end{tabular}

Table (5): Post procedure complications in the study groups.

\begin{tabular}{|l|c|c|}
\hline & Frequency & Percent \% \\
\hline Minor complication & & \\
\hline $\begin{array}{l}\text { Post embolization } \\
\text { syndrome }\end{array}$ & 3 & 15 \\
\hline Pelvic infection & 1 & 5 \\
\cline { 1 - 1 } Transient amenorrhea & 1 & 5 \\
\cline { 1 - 3 } Major complication & \multirow{2}{*}{2} & 10 \\
\hline Bleeding recurrence & 2 & \\
\hline
\end{tabular}

Figure (1): Post embolization procedure response of patient's symptoms. 


\section{Cases Presentation:}

Case 1.Premenopausal 32-year-old patient, married, multipara, complaining from menometrorrhagia, dysmenorrhea, anemia, and bulk symptoms.

MRI showed enlarged uterus with single large anterior wall interstitial uterine fibroid. (Fig $2 \mathrm{~A}$ ) Bilateral uterine artery embolization through single right sided femoral puncture access. (Fig $2 \mathrm{C}, \mathrm{D}, \mathrm{E}$, F). Using TAGM (500-700 $\mu \mathrm{m})$ and PVA (700-900 $\mu \mathrm{m})$.

Follow up after 6 months by MRI showed $34 \%$ reduction of uterine volume and $35 \%$ reduction of fibroid volume. (Fig 2 B)

Control of bleeding with correction of anemia and bulk symptoms.

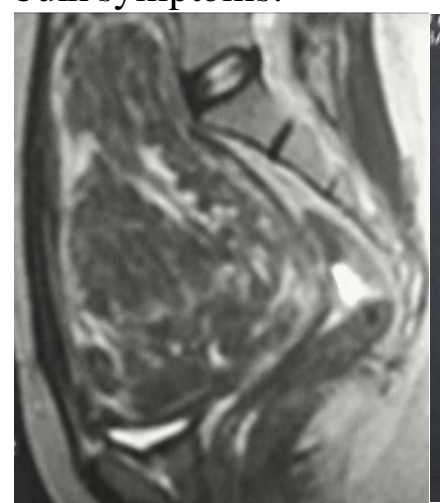

A

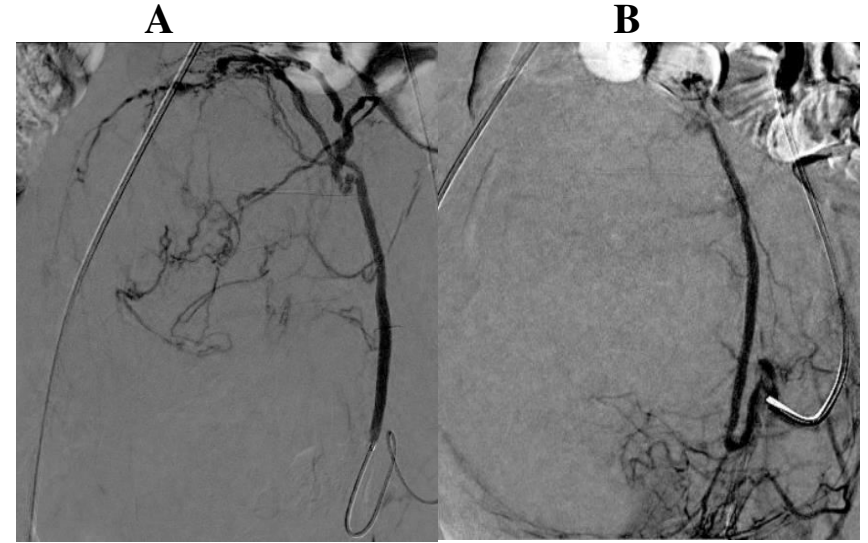

D

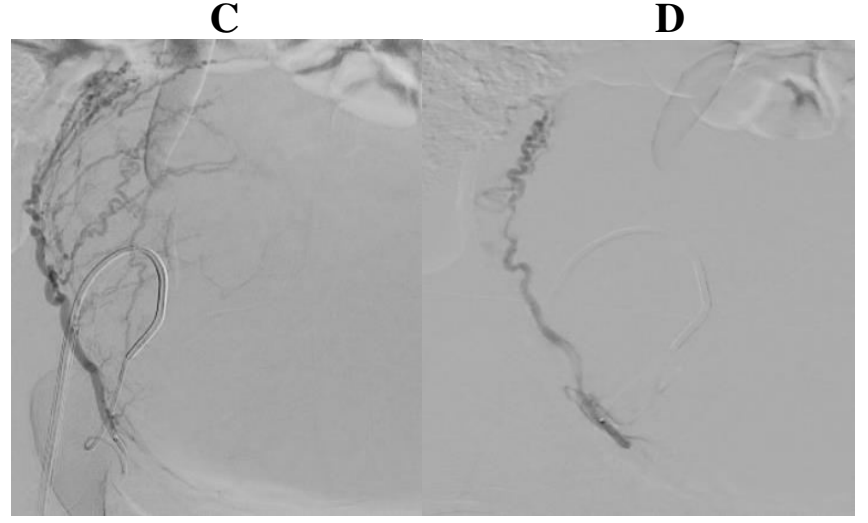

$\mathbf{E}$

$\mathbf{F}$

Figure 2 (A) Pre embolization \&(B) postembolization Sagittal T2W MRI images showing reduction of uterine and fibroid volumes.(C) Pre-
embolizationDSA: catheterization of the left uterine artery showing fibroid tumoral blush. (D) post-embolization: showing absence of the blush. (E) Pre-embolizationDSA: catheterization of the right uterine artery showing fibroid tumoral blush. (F)post-embolizationDSA: shows absence of the blush.

Case 2.Premenopausal 42-year-old, diabetic patient, married, multipara, complaining from menorrhagia, dysmenorrhea, dyspareunia, pelvic pain and bulk symptoms.

MRI showed enlarged uterus with increased junctional zone thickness measuring about $13 \mathrm{~mm}$, parametrial varices (left gonadal vein $8 \mathrm{~mm}$ ), no uterine fibroids (Fig $3 \mathrm{~A}$ )

Bilateral uterine artery embolization through single right sided femoral puncture (Fig $3 \mathrm{C}, \mathrm{D}, \mathrm{E}, \mathrm{F}$ ). Using PVA $(355-500 \mu \mathrm{m})$

Follow up after 6 months by MRI showed $40 \%$ reduction of junctional zone thickness. Reduction of parametrial varices (left gonadal vein $4 \mathrm{~mm}$ ).(Fig 3 B)

Control of bleeding with correction of bulk symptoms and improvement of pelvic congestion.
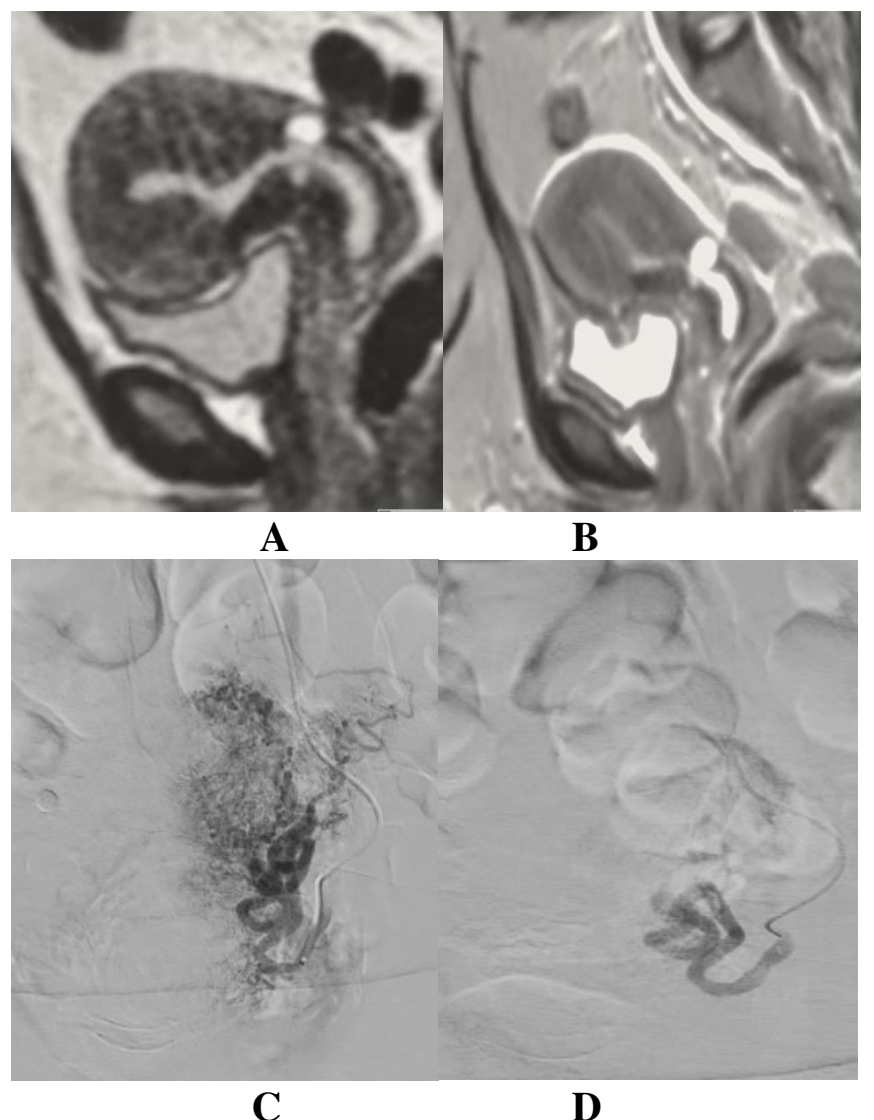

C 


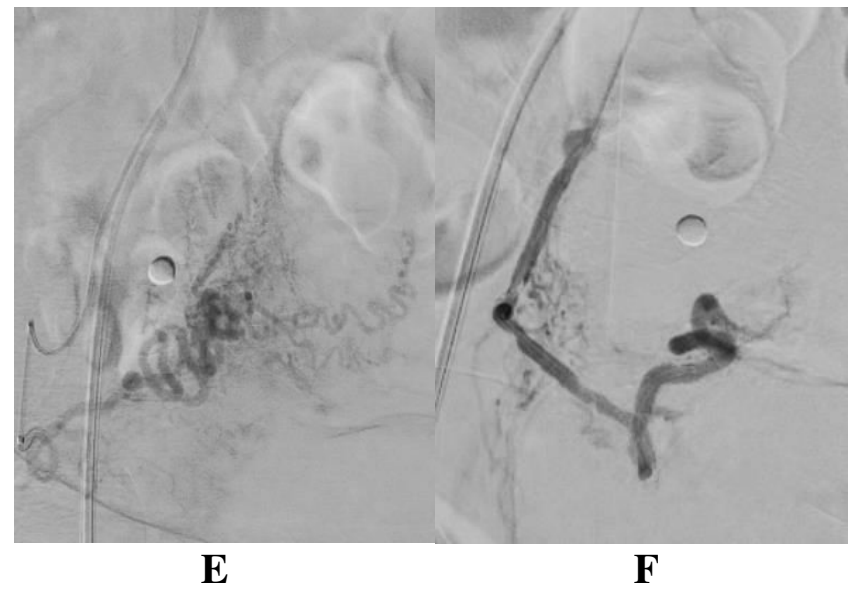

Figure 3 (A): Pre embolization \&(B) postembolization Sagittal T2W MRI images showing reduction of uterine volume and JZ thickness.(C) Pre-embolizationDSA: catheterization of the left uterine artery showing opacification of the uterine vascular bed. (D) post-embolizationDSA: shows absence of the blush. (E) Pre-embolizationDSA: catheterization of the right uterine artery showing opacification of the uterine vascular bed. (F)postembolization DSA: shows absence of the blush.

\section{Discussion:}

Uterine artery embolization was first reported as an effective uterine bleeding treatment option in 1995 and then it has been proven to be an efficacious and safe method with a relatively high success rate in minimizing pain, bulk symptoms and bleeding linked to uterine fibroids (Maciel et al., 2017).

Uterine artery embolization (UAE) is minimally invasive, allows preservation of uterus, and has a low complication rate (Kang, 2012). Therefore, UAE has emerged as a possible treatment option for patients with symptomatic adenomyosis.

This study included 20 patients referred for UAE, their ages ranged from 21- 55 years old with mean age of $38.90 \pm 7.026$ years. This is consistent with the results of (Abramowitz et al., 2009) that studied a sample of 25 patients with mean age of 31.8 years.

All patients were presented to us by abnormal uterine bleeding due to different causes, 16 patients (80\%)were complaining from anemia, three patients required blood transfusion (15\%). 12 patients (60\%) complained from Urinary symptoms. All patients complained of pelvic pain, and $8(40 \%)$ of them had sciatica too, and $6(30 \%)$ patients had bowel symptoms. In a study by (Walker et al., 2002), the most common presenting symptom was abdominal swelling (98\% of patients). $78 \%$ of their patients had menorrhagia and $59 \%$ had menstrual pain. At the same study, pressure symptoms, urinary frequency and sciatica were encountered in $82 \%, 35 \%$ and $32 \%$ of the women, respectively. $46 \%$ of women had suffered period-induced anemia $(\mathrm{Hb}<12.0 \mathrm{~g} / \mathrm{dL})$ and $12 \%$ of them required blood transfusion.

Bilateral uterine artery embolization was done in 11 out of 12 patients of the study with uterine fibroid $(91.7 \%)$ while only one case had unilateral UAE in which the left uterine artery was the sole dominant supply to the fibroid. The contralateral right uterine artery was normal in size and supplying only normal myometrium. The bleeding stopped completely after the procedure and the bulk related symptoms have completely improved by using the unilateral approach. This agree with a study by (Bratby et al., 2007), in which 48 patients with uterine fibroids were treated by unilateral UAE with $85.7 \%$ of cases reported improvement or resolution of menorrhagia and a similar improvement or resolution in dysmenorrhea and bulk-related symptoms in $85.7 \%$ and $76.2 \%$, respectively, at 1 year.

In our study, we used PVA particles as an embolizing material in ten patients with uterine fibroids. It was used in combination withTAGM in most of our patients (9 out of 12). PVA was used alone in only one patient. Particle size used were $355-500 \mu \mathrm{m}, 500-710 \mu \mathrm{m}$ and $700-900 \mu \mathrm{m}$. TAGM were used alone in two patients. Particle size used were $355-500 \mu \mathrm{m} \& 500-700 \mu \mathrm{m}$. Usage of PVA or TAGM alone was equally effective to usage of them in combination in reducing uterine and fibroid volume without comprising clinical or radiological outcomes. This agrees with a study done by (Farrell et al., 2020),comparing the results and cost-efficacy of TAGM alone versus combined TAGM and gelatin sponge embolization in UAE and concluded that the combined use of TAGM/GS reduced the mean cost of embolic agents by $42 \%$.

In this study, the range (Mean $\pm \mathrm{SD})$ of the uterine and dominant fibroid volume/cm 3 pre UAE were 60-1134(332.52 $\pm 258.50 \mathrm{cc}), 40$ -

$768(178.85 \pm 196.34 \mathrm{cc})$ respectively, and the range $($ Mean \pm SD) of the uterine and dominant fibroid volume $/ \mathrm{cm} 3$ post UAE were 54-630 (203.55 $\pm 150.60 \mathrm{cc}), \quad 18-252 \quad(75.71 \pm 64.85 \mathrm{cc})$ respectively, with statistically significant difference between pre and post procedure according to 
volume of uterus/cm 3 and volume of dominant fibroid $/ \mathrm{cm} 3$ as $\mathrm{p}$ value $<0.001$, and 0.023 respectively and average uterine and dominant fibroid volumes loss of $39 \%$, and $57 \%$ respectively.

These are constant with the results of (Liang et al., 2012), that reported uterus and dominant fibroid volume/cm3 ranged from $77-1767$, and 91-897 respectively and uterine and dominant fibroid volume reduction about 50\%, and $60 \%$ respectively. On the other hand, (Aly et al., 2018), recorded average uterine and dominant leiomyoma volumes of 770 (range: $330-1193 \mathrm{~cm} 3$ ), 300.5 (range: $80-500 \mathrm{~cm} 3$ ) respectively, and average uterine and dominant fibroid volume reduction were $30 \%$, and $44 \%$ respectively. While (Farrell et al., 2020), study revealed reduction in uterine volume $40.7 \%$ in the TAGM group, $44.4 \%$ in the TAGM/gelatin sponge group and dominant leiomyoma volume (TAGM 47.6\%, TAGM/gelatin sponge $50.1 \%$ ) at six months.

In our study 3 out of 4 patients (75\%) with symptomatic adenomyosis showed correction of menorrhagia and menometrorrhagia with no longer bleeding post embolization and complete correction of anemia in 3 patients who already had low $\mathrm{Hb}$ level from the start. Only one patient $(25 \%)$ showed recurrence of bleeding, refused receiving 2nd session of UAE, and underwent hysterectomy. All patients showed dramatic improvement of bulk and urinary symptoms as well as pelvic pain. So, we agree with(Kim et al., 2021), 163 patients underwent UAE. There were statistically significant differences in bleeding score, and pain score at three months after UAE $(\mathrm{P}<0.001$, and $\mathrm{P}<0.001$ respectively $)$.

The range of Junctional zones thickness were 13$20 \mathrm{cc}$ (mean $=14.875 \pm 3.42 \mathrm{cc})$ on preembolization US and MRI images compared to 12$18.5 \mathrm{cc}$ (mean $=14.00 \pm 3.028 \mathrm{cc}$ ) on postembolization images, this equals $5.6 \%$ reduction in Junctional zone and $p$ value 0.003 . This agree with a study by (Kitamura et al., 2006), where nineteen patients with symptomatic adenomyosis on MRI were referred for UAE. Uterine volume decreased significantly after UAE $(\mathrm{p}<0.01)$. The mean uterine volume reduction was $25.1 \%$. Junctional zone thickness decreased significantly $(\mathrm{p}<0.001)$.

On reviewing data in the literatures, there is deficiency regarding the role of endovascular UAE in treatment of DUB. To our knowledge, the role of UAE in the treatment of DUB has not been investigated before in a large study. Only 2 cases were reported in the literature. The first one by (Bowkley et al., 2007), who used UAE in the management of menorrhagia in a 12-year-old girl presented with first onset life threatening menorrhagia following failure of response to standard medical or gynaecological measures. The second case was reported by (Kho and Mathur, 2015), where UAE was used in the treatment of menorrhagia in a 35-year-old patient with acute dysfunctional uterine bleeding following failure of response to standard medical treatment However, she presented a year later with another episode of acute DUB that required a repeat UAE. In these two cases, however, UAE was only used as a successful method to control the acute bleeding, but the patients were not followed up afterward.

We encountered few complications in our study, perhaps reflecting the expertise in the participating center. Most of them were in the acceptable range and were treated conservatively. 3 patients had post-embolization syndrome in form of abdominal and pelvic pain, transient vomiting, and fever. one patient developed post procedure mild pelvic infection with infected vaginal discharge, and delayed return of menses (transient amenorrhea) in one case. Post procedure recurrence of bleeding occurred in two patients $(10 \%)$ after the procedure (within 6-12 months after embolization) and the two underwent hysterectomy.

In a study by (Katsumori et al., 2021), 28 out of 111 patients $(25 \%)$ had adverse effects after the procedure. One patient had one major complication (permanent amenorrhea), whereas the remaining 27 patients had minor complications as follows: transient amenorrhea, pain, leiomyoma expulsion, deep vein thrombosis, hematoma at the puncture site, and delayed fever.

The main limitations of our study were that; the study included small number of patients in a single institution and single operator study.

\section{Conclusion}

Uterine artery embolization is considered minimally invasive, safe, and effective methods that play an important role in treatment of variable types of abnormal uterine bleeding causes, aiming for uterine preservation and avoiding hysterectomy 
giving the chance for future fertility. It is the surgery of the future.

We recommend further research on a larger number of patients and a longer period of follow up to confirm the findings.

\section{References}

Abramowitz SD, Israel GM, McCarthy SM, Pollak JS, White Jr RI, Tal MG (2009). Comparison of four embolic materials at uterine artery embolization byusing postprocedural MR imaging enhancement. Radiology, 250(2):482-7.

Aly WR, Abdullah TM, Botros SM (2018). Measurement of uterine leiomyomata volume pre and post uterine artery embolization aided by MRI. The Egyptian Journal of Hospital Medicine, 71(4):3007-16.

Armstrong AA, Kroener L, Brower M, Al-Safi ZA (2019). Analysis of reported adverse events with uterine artery embolization for Leiomyomas. Journal of minimally invasive gynecology, 26(4):667-70.

Benagiano G, Brosens I, Habiba M (2014). Structural and molecular features of the endomyometrium in endometriosis and adenomyosis. Human reproduction update, 20(3):386-402.

Bowkley CW, Dubel GJ, Haas RA, Soares GM, Ahn SH (2007). Uterine artery embolization for control of life-threatening hemorrhage at menarche: brief report. Journal of Vascular and Interventional Radiology, 18(1):127-31.

Bratby MJ, Ramachandran N, Sheppard N, Kyriou J, Munneke GM, Belli AM (2007). Prospective study of elective bilateral versus unilateral femoral arterial puncture for uterine artery embolization. Cardiovascular and interventional radiology, 30(6):1139-43.

Farrell TP, Garvey C, Adams NC, Mulholland D, Ryan JM, Guiney M, et al., (2020). Comparison of outcomes and cost-effectiveness of trisacryl gelatin microspheres alone versus combined trisacryl gelatin microspheres and gelatin sponge embolization in uterine fibroid embolization. Acta Radiologica, 61(9):1287-96.

Kang BC (2012). treatment Failure after Uterine artery embolization for symptomatic Uterine Fibroids: significance of ovarian arterial Collateral
Vessels in predicting the outcome. The Ewha Medical Journal, 35(2):102-9.

Katsumori T, Yoshikawa T, Sasakura Y, Yasumura T, Hisano $M$ (2021). Timing of Uterine Artery Embolization for Leiomyoma during the Menstrual Cycle. Journal of Vascular and Interventional Radiology, 32(3):332-8.

Kho CL and Mathur M (2015). Uterine artery embolisation for acute dysfunctional uterine bleeding with failed medical therapy: a novel approach to management. Case Reports, 2015, p. bcr2014204446.

Kim JY, Song YG, Kim CW, Lee MO (2021). Uterine artery embolization using gelatin sponge particles for symptomatic focal and diffuse adenomyosis. Clinical and Experimental Obstetrics \& Gynecology, 48(1):59-65.

Kitamura Y, Allison SJ, Jha RC, Spies JB, Flick PA, Ascher SM (2006). MRI of adenomyosis: changes with uterine artery embolization. American Journal of Roentgenology, 186(3):85564.

Liang E, Brown B, Kirsop R, Stewart P, Stuart A (2012). Efficacy of uterine artery embolisation for treatment of symptomatic fibroids and adenomyosis-An interim report on an A ustralian experience. Australian and New Zealand Journal of Obstetrics and Gynaecology, 52(2):106-12.

Maciel C, Tang YZ, Sahdev A, Madureira AM, Vilares-Morgado $P$ (2017). Preprocedural MRI and MRA in planning fibroid embolization. Diagnostic and Interventional Radiology, 23(2):163.

Marnach ML and Laughlin-Tommaso SK (2019). Evaluation and Management of Abnormal Uterine Bleeding. Mayo Clinic Proceedings, 94 (2): 326-335.

Moss J, Christie A (2016). Uterine artery embolization for heavy menstrual bleeding. Women's Health, 12(1):71-7.

Munro MG (2016). Best Practice \& Research Clinical Obstetrics and Gynaecology. Best Practice $\&$ Research Clinical Obstetrics and Gynaecology, 30:1-20.

Munro MG (2017). Practical aspects of the two FIGO systems for management of abnormal uterine 
bleeding in the reproductive years. Practice \& Research Clinical Obstetrics \&Gynaecology, 40: 322.

Stewart EA (2015). Clinical practice. Uterine fibroids. The New England journal of medicine, 372(17):1646-55.

Walker WJ and Pelage JP (2002). Uterine artery embolisation for symptomatic fibroids: clinical results in 400 women with imaging follow up. BJOG: an international journal of obstetrics and gynaecology, 109(11):1262-72. 